\title{
COLLABORATING FOR PEACE
}

\author{
AN ANALYSIS OF NETWORKS \\ OF COOPERATION IN SOMALIA
}

Dominik Balthasar and Anja Osei

Authors

Dr Dominik Balthasar is a senior researcher at Swisspeace's statehood programme and lecturer at the University of Basel, working on issues pertaining to conflict, fragility, and development. He has held fellowships with a range of university institutes and think tanks, and consulted with the UN and World Bank, among others.

Dr Anja Osei is a senior research fellow and lecturer at the Chair of International Politics and Conflict Management, University of Konstanz. Her work focuses on elite sociology, democratization, and conflict studies. She holds an MA and $\mathrm{PhD}$ in African Studies.

Konstanzer Online-Publikations-System (KOPS)
Summary $\quad$ URL: http://nbn-resolving.de/urn:nbn:de:bsz:352-2-cv2o9on4y2kc4

Peace and reconciliation are fundamentally about cooperation. Understanding the nature and shape of actors' networks allows us to draw important inferences about the degree and kind of cooperation. Denser and more decentralDominik Balthasar and Anja Osei, Collaborating for Peace: An Analysis of Networks of Cooperation in Somalia. In: War and Peace in Somalia: National Grievances, Local Conflict and Al-Shabaab. Edited by Michael Keating and Waldman Matt, Oxford University Press (2018). (C) Oxford University Press. 
ized networks enable a faster flow of information and more inclusive decisions. Denser networks also help to increase mutual trust among network participants, which is crucial for fostering peace and reconciliation.

This research project sets out to capture and analyse the web of national and international networks of cooperation in Somalia. Applying social network analysis to identify patterns of cooperation among international as well as between international and national actors central to the delivery and implementation of humanitarian and development assistance, the project's objective is to better understand prevailing practices of cooperation and their implications for peace and reconciliation.

In order to uncover patterns of cooperation, this project collected primary data through a voluntary online survey among international actors with a mandate to support Somali reconstruction. One of the key findings is that networks of cooperation remain-despite a considerable longevity and plurality of national and international aid organizations - surprisingly sparsely connected. Another major finding concerns the fact that even international non-governmental organizations seem to collaborate more with the host government than with civil society counterparts.

Given the confined scope of both the research project and the survey response rate, caution should be exercised in drawing conclusions about policy recommendations. Nonetheless, the research findings do suggest a need for, and opportunity to bring about, enhanced collaboration between the plethora of national and international actors in order to increase the impact of international aid toward supporting peace and reconciliation in Somalia. Furthermore, cooperation does not necessarily need to take on a formal character. Informal networks may, in fact, be at least as effective in enhancing trust and cooperation, and therefore contributing to peace and reconciliation.

\section{Introduction}

Having been labelled the "quintessential failed state", ${ }^{1}$ and having consistently featured prominently in diverse fragile states rankings, ${ }^{2}$ Somalia has drawn significant international attention. Consequently, the country has been marked by multidimensional involvement on the part of the international community, spanning from humanitarian aid to counter-terrorist interventions. The proliferation of donors and the fragmentation of aid, which has advanced particularly over the course of the past quarter century, has led to repeated calls for the need of increased coordination. These calls have been 
well-received in an environment in which donors and recipients alike have expressed support for improved aid coordination in order to enhance aid effectiveness and accountability. ${ }^{3}$ Moreover, it is recognized that achieving peace and reconciliation in Somalia inherently hinges on cooperation.

This briefing paper provides some initial insights into patterns of contemporary cooperation in Somalia. Applying social network analysis methodology to international aid cooperation in Somalia, this paper asks how current national and international networks of cooperation take shape. What does inter-agency collaboration look like in Somalia? Gaining a better understanding of prevailing networks of cooperation is crucial to improve aid effectiveness and to uncover how problem-framing and decision-making are shaped.

A greater understanding of networks of cooperation also helps us to identify ways of enhancing joint efforts to build peace and stability. Peace and reconciliation processes, by definition, require collaboration, which in turn is affected by the nature of social networks. Broadly speaking, dense and decentralized networks allow a faster flow of information, greater mutual understanding and more effective problem-solving. Such networks are also more inclusive, encompassing diverse stakeholders, which is critical for trust-building and reconciliation.

\section{Networks of Cooperation in Somalia}

\section{International Aid in Somalia}

Somalia provides a challenging operating context for international aid agencies. Efforts undertaken by the international community to support Somalia in rebuilding a more peaceful and stable state have drawn much criticism. Thereby, internationally brokered peace conferences have generated accusations of a self-interested "aid-industry" that has, for most parts, operated in a "remote control" modus operandi from Nairobi, Kenya. Particularly, Somalis have tended to remain critical of and sceptical toward external assistance. This is partly due to historical experiences, when large quantities of aid were diverted to warlords, militias, or a confined group of elites.

Somalia obtains significant amounts of international aid. According to World Bank data, the Horn of Africa nation received US $\$ 1.25$ billion in net official development assistance and official aid in 2015. ${ }^{4}$ According to the Aid Coordination Unit (ACU) within the Office of the Prime Minister of Somalia, the country's international development partners reported US\$675 
million in aid for development for $2015 .^{5}$ Accompanied by nearly US\$593 million in humanitarian aid, official development assistance reached US $\$ 1.3$ billion in 2015 (which excludes military aid and peacekeeping contributions). ${ }^{6}$ Major development partners, in terms of financial contributions, are the UN and the World Bank (multilateral) and the United Kingdom and Norway (bilateral). The significant increase of aid over the course of the past decade (up from approximately US $\$ 400$ million in 2007) renders aid coordination and thus, agency cooperation, crucial—for reasons of both efficiency and effectiveness.

Somalia has witnessed a range of coordination mechanisms. The country is part of the G7+ and the New Deal for Engagement in Fragile States, both of which are designed to enhance the alignment of official development assistance. There is a range of coordination mechanisms in place in order to facilitate cooperation and coordination. ${ }^{7}$ Official development finance has increasingly been channelled through the Somalia Development and Reconstruction Facility (SDRF), a financing architecture that provides strategic guidance for development activities in Somalia. While an assessment of the effectiveness of these coordination instruments promises to be insightful, it is beyond the scope of this paper to do so. Rather, this briefing paper seeks to document and analyse de facto networks of cooperation "on the ground" in order to foster a critical debate about current levels of national and international cooperation, as well as about how collaboration among diverse actors could be improved. The fundamental rationale is that increased cooperation not only results in more effective aid but also fosters greater mutual understanding.

\section{Conceptual Framework}

While the dominant canon of scholarship on peacebuilding and state-building centres on the role of institutions, an incremental realization of the need of "bringing agency back in" has taken hold. Drawing on a wide scholarshipparticularly in African studies - that emphasizes the role of informal, often clientelistic, relationships that coexist with formal institutions, ${ }^{8}$ a buoying literature points towards the importance of clientelism in particular ${ }^{9}$ and actor relationships more generally ${ }^{10}$ in order to understand state trajectories. In other words, networks have increasingly been recognized as being of crucial importance in coming to grips with state performance. ${ }^{11}$

Acknowledging the significance of political networks for national development, this research project adapts a network lens to the sphere of international 
cooperation. The fundamental argument is that the effectiveness of international assistance significantly hinges on networks of cooperation that international actors entertain with national counterparts. While it has been acknowledged that actors and their relations can be crucial for the success of state-building endeavour, ${ }^{12}$ our empirical insights in these structures have often remained limited. We argue that the mapping of international actor relationships adds an important and empirically grounded actor-centric aspect to the prevailing literature of state-building.

In order to identify and analyse national and international networks of cooperation, this paper uses the method of social network analysis (SNA). Social networks consist of nodes, which are usually the actors, and links or ties, which denote the relationships between them. The network itself consists of chains of interconnected dyads. The ties in a network can be directed, meaning that one node is a sender of something that flows through a network (such as information or resources) while another node acts as a receiver. A range of network measures enable analysis of the quality and nature of such webs of relationships.

In this paper, we use a number of measures to describe the structure of the network. The density measure is a basic description of the global interconnectedness of all nodes. Density is calculated by dividing the number of ties present in a network by the number of theoretically possible ties. The density measure takes on values between zero (when no ties exist at all) and one (for a complete network in which every actor is connected to every other actor). Degree centrality simply looks at the absolute number of connections that a node has. It can be further distinguished between in-degree centrality which relates to the number of ties a node receives and out-degree centrality, which relates to the number of ties that a node transmits. "Betweenness" centrality measures how often a node lies on the shortest path between two other nodes. Actors with high betweenness centrality scores are usually powerful actors that can control and dominate the flow of resources in a network. Centralization, as a property of whole networks, looks at the differences between the centrality scores of the most central node and those of all other points.

\section{Research}

\section{Methodology}

This briefing paper is based on an online survey conducted among international actors active in Somalia. On the basis of a list of agencies provided by 
the United Nations, we contacted some 120 international actors, of whom 31 filled out the questionnaire. The response rate, thus, stands at roughly $25 \%$, which puts some limitations on the survey's explanatory power (see below). About half of all responses to the survey request were provided for by international non-governmental organizations (NGOs, 47\%), followed by UN agencies and other multilateral organizations (26\%), with research organizations/ think tanks (9\%), bilateral donors (7\%), and others (11\%) following suit. In terms of the organizations' field of activity as indicated by the respondents themselves, some $37 \%$ of all respondents are active in the field of development cooperation, $14 \%$ in humanitarian aid, and $12 \%$ in political assistance, with the remainder classifying as research (5\%), security (2\%), and other (30\%).

With a view to the questionnaire, the respondents were asked to name all organizations with which they cooperate, followed by a number of questions on the nature and extent of their cooperation. From these ego networks, the global structure of cooperation was constructed (see Figure 1). In order not to unduly expose the specific networks of cooperation a particular organization maintains, the subsequent graphs are displayed without attributing organizations' names to the respective nodes.

Figure 1: Networks of cooperation

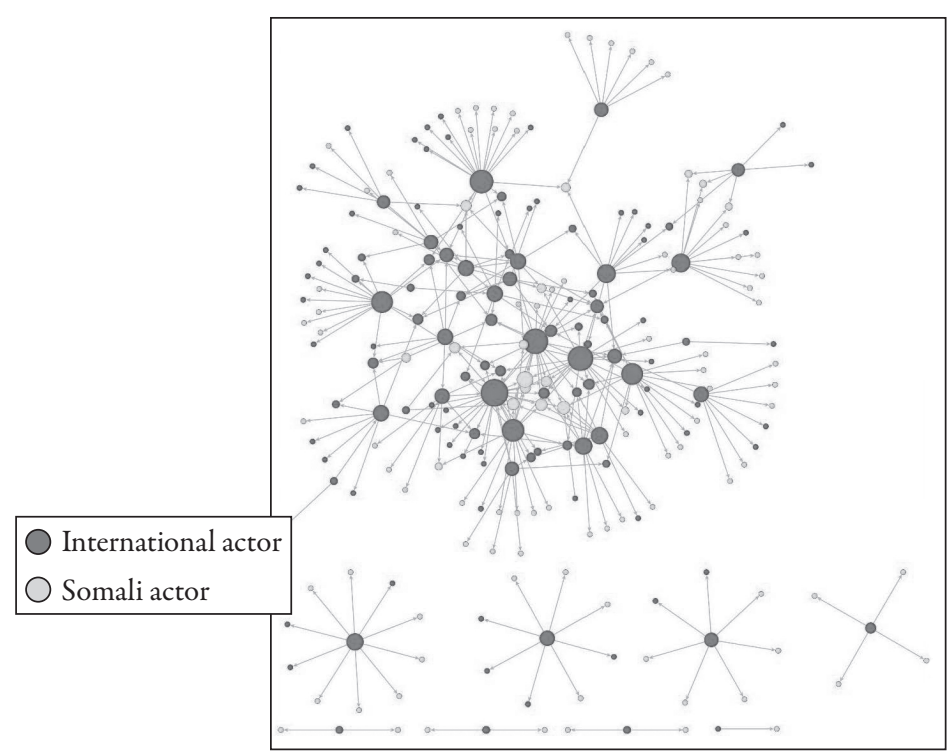




\section{Findings}

A number of findings follow from the research data generated. Taking the entirety of the network composed of national and international actors as a unit of analysis, what emerges is that it is composed of a more integrated core of international organizations that is surrounded by a less densely connected periphery of national counterparts (see Figure 1). Interestingly, all those actors marked by a high degree of centrality are representatives of the international community, with no Somali actor taking a more central position in the prevailing web of relationships. While the data do need to be taken with a pinch of salt, this finding opens up a number of questions with regard to the respective roles played by national and international actors. Although the New Deal for Engagement in Fragile States seeks to put national counterparts into the driving seat, it appears that much humanitarian aid and development assistance coordination happens without their participation.

When confining the scope of analysis to the network of cooperation among international actors (see Figure 2), the data suggest that only 2.4 per cent of all possible connections are realized within the network. While this density is somewhat greater as compared to the network of cooperation between international actors and their national counterparts (see below), it points toward a

Figure 2: Type of networks of cooperation among international actors
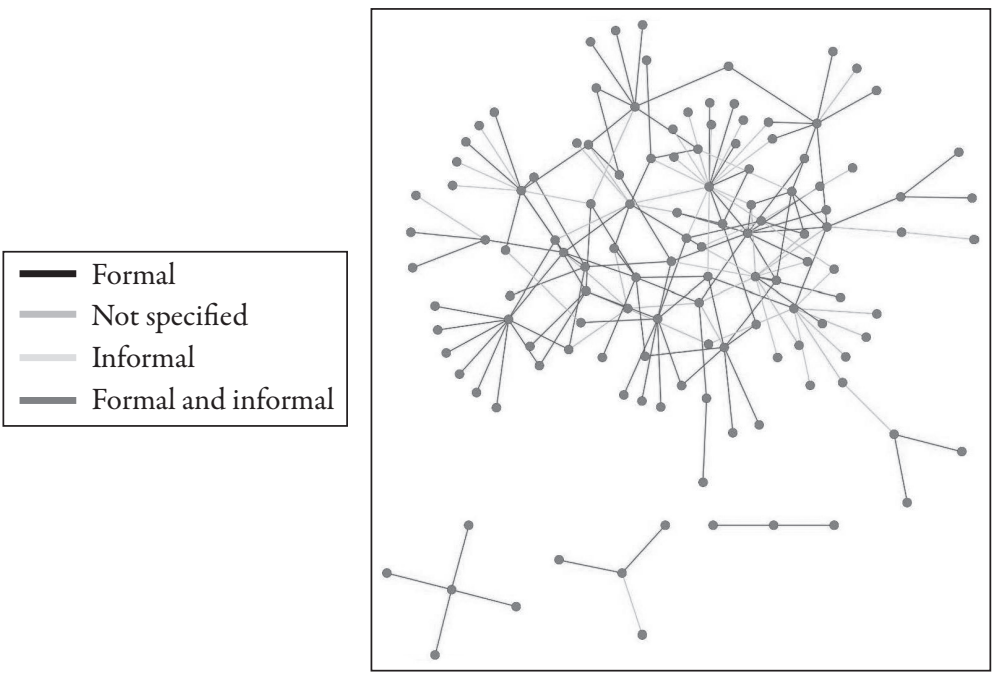
sparsely developed network. Moreover, it is interesting to note that the information provided by the survey respondents indicates that there are no reciprocal ties-although actors are connected with one another via third parties, direct reciprocal ties are missing. Moreover, the centrality measure of 13 per cent suggests that the network, which consists of four distinct components, is rather decentralized in nature. In contrast to highly centralized networks in which a few actors are able to control the flow of information and other resources, decentralized networks point toward more even and inclusive relationships. The actor with the highest measures for in-degree, out-degree, and betweenness centrality is the United Nations Assistance Mission in Somalia (UNSOM), which constitutes the most critical actor within the web of international actors' cooperation. Remarkably, however, while UNSOM takes centre stage when it comes to the network of cooperation among international actors, UNSOM is-according to this dataset-much less present when it comes to collaborations with Somali counterparts.

When considering the network of cooperation between international actors and national counterparts (see Figure 3), one of the most pronounced findings is that this network is relatively sparse. According to the respective density measure, and due to the fact that the average actor exhibits only two ties, the network relies on only 1.5 per cent of all possible connections. What is more, the network is little centralized, but relatively fragmented, constituting itself out of 17 distinct components. According to our survey data, the network's most central actors are the Federal Government of Somalia, followed by the regional governments. This indicates that the public authorities at national and regional level constitute the most important cooperation partners for the collectivity of international actors.

Conversely, Somali civil society organizations appear to be the least important cooperation partners for international actors-indicated by much lower density measures within this network. In light of the fact that nearly half of all survey respondents are international NGOs, this is somewhat surprising, though it can be taken as an indication that international NGOs also rely significantly on cooperation with national and regional public bodies.

Moreover, the data suggest that nearly two-thirds of all cooperation between international actors and Somali counterparts flows along formal mechanisms of cooperation, whereas informal cooperation and the combination of formal and informal cooperation make up for 16 per cent and 18 per cent of relationships, respectively. There is no clear pattern in the distribution of formal and informal ties; many actors have both formal and 


\section{COLLABORATING FOR PEACE}

Figure 3: Type of networks of cooperation between international and Somali actors
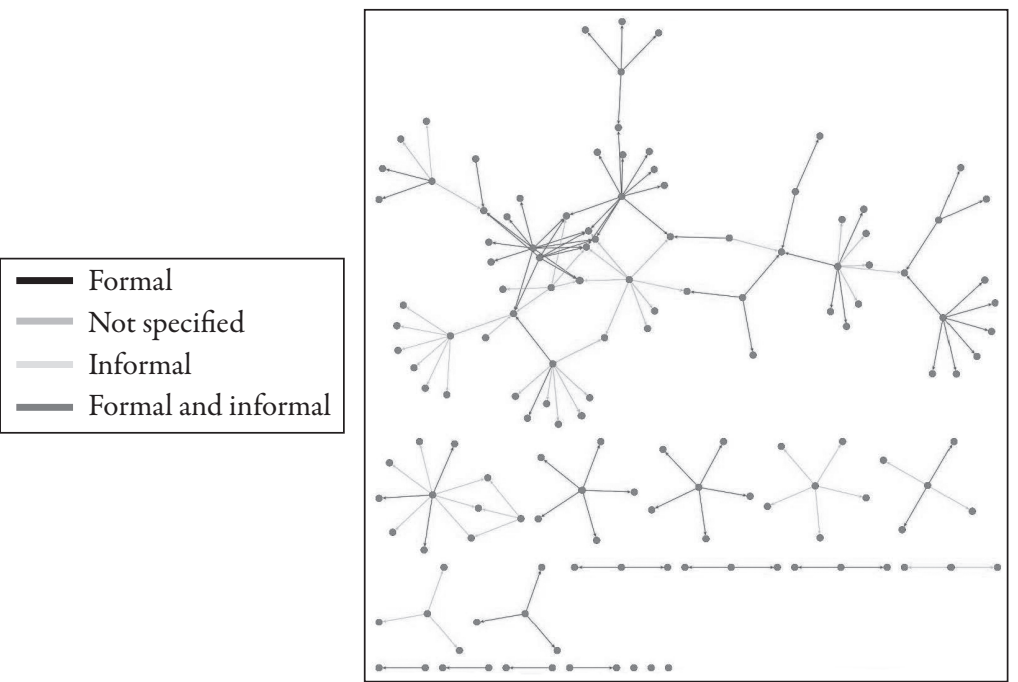

informal ties. This indicates that the type of cooperation depends on the particular situations in which actors decide to link up with others in one or the other way. That said, these insights into patterns of formal and informal cooperation are strongly shaped by the survey respondents. If so-called nontraditional donors, local staff, or Somali organizations were to constitute part of the respondents, the resulting data would likely differ in important ways.

A number of additional findings are worth highlighting. First, the data also show that there is no consensus among the international actors of which (individual or collective) actor most decisively shapes the future of Somalia. Yet, among the 71 distinct entries made in the context of this question, the Federal Government of Somalia leads the chart with nine mentions-followed by the UN (seven) and AMISOM, donor community, and President Farmaajo (each six). Thus, according to the perception of representatives of the international community, the UN are accorded a significant role in shaping the future of Somalia. Second, the survey also indicates that international aid agencies remain very open to cooperation with a broad range of actors. The question about which Somali partners international agencies would not consider working with hardly triggered any response. That said, the fact that the question about potential Somali cooperation partners also triggered only few answers may point to either a saturation or lack of imagination when it comes to 
broadening networks of cooperation. Third, and here finally, our data show that none of the respondents mentioned the Aid Coordination Unit (ACU) at the Office of the Prime Minister and the Ministry of Planning and International Cooperation, ${ }^{13}$ the Somali Federal Government's main bodies engaged in promoting the coordination and management of official development finance. While the possibility that this body was not mentioned roots in the nature of the questionnaire, it is telling that this coordination mechanism does not feature at all in the responses given by the survey participants.

\section{Caveats}

Although these findings provide some instructive insights into the nature of cooperation in Somalia, the underlying research exhibits a number of caveats. First, at roughly 25 per cent, the response rate remained confined, unfortunately, rendering the data gathered incomprehensive, limiting its representativeness. Second, the survey results are not guarded against self-selection bias among the respondent organizations, as participation was voluntary rather than obliged. Third, the data rely on information provided for by international aid agencies, thus being indicative of the "international community's" subjective viewpoint, rather than a more objective and holistic assessment of the state of affairs. A more comprehensive follow-up project will need to take these caveats into consideration in order to allow for a more detailed and precise assessment of national and international networks of cooperation in Somalia.

\section{Conclusions}

Suggesting that networks of cooperation in Somalia remain deficient, this briefing paper concludes that national and international actors should consider enhancing and diversifying their relationships. In view of the general emphasis put on donor and aid coordination ${ }^{14}$ at policy level, it remains astonishing that the networks of cooperation in a donor-dependent country such as Somalia remain so confined.

Scholarship on social networks agrees that different kinds of networks exert different influences on actors' ability to exchange information, build mutual understanding and trust, and coordinate their activities in order to develop solutions to challenges they face. ${ }^{15}$ Dense networks facilitate cooperation, because an increase in connectivity leads to faster and better solutions in coordination simulations. ${ }^{16}$ More tightly connected networks are likely to enhance 
the effectiveness of measures taken by national and international actors in response to conflict and fragility in Somalia. Such networks are also likely to contribute to trust-building and the emergence of behavioural norms, which are crucial elements of state-building.

Yet, as this research shows, there seems to be a dearth of cooperative networks among and between national and international actors in Somalia. Given the positive implications that dense networks have for cooperation, and for peace and reconciliation, the prevailing situation in Somalia does not appear to be conducive for peacebuilding.

\section{Recommendations}

This analysis has provided some initial insights into networks of cooperation in Somalia, and the implications for peacebuilding. While the limited scope of both the research project and the survey response rate do not justify a wide range of policy recommendations, it is clear that much remains to be explored. It is therefore recommended that a more comprehensive quantitative analysis of cooperation in Somalia is undertaken, as well as a more qualitative analysis of its nature. If a more encompassing study, depicting national and international networks of cooperation, were to be carried out, a clearer picture would emerge as to which actors need to be connected in order to enhance the prospects for peace and reconciliation in Somalia.

Three further recommendations can be made. First, given the various advantages of denser networks, national and international actors supporting Somalia's transition out of conflict and fragility should enhance their collaboration and seek to strengthen their respective networks. Second, as trust-building tends to operate at an individual rather than an institutional level, greater efforts should be made to strengthen informal networks of cooperation. Third, international actors should improve collaboration with Somali civil society organizations, which might include an intensification of existing ties, as well as the formation of new partnerships with a broader range of organizations. 
